\title{
Efeitos da aplicação tópica de hormônio juvenil sobre o desenvolvimento dos ovários de larvas de operárias de Apis mellifera Linnaeus (Hymenoptera,Apidae)
}

\author{
William Fernando Antonialli-Junior ${ }^{1} \&$ Carminda da Cruz-Landim²
}

${ }^{1}$ Laboratório CInAM, Universidade Estadual do Mato Grosso do Sul (UEMS), Rodovia Dourados/Itahum, KM 12,Caixa Postal 351, 79804-970 Dourados-MS. antonialli@uems.br

${ }^{2}$ Departamento de Biologia, Universidade Estadual Paulista (UNESP), 13506-900 Rio Claro-SP. cclandim@rc.unesp.br

\begin{abstract}
Effect of topic application of juvenile hormone on the ovarian development of worker larvae of Apis mellifera Linnaeus (Hymenoptera, Apidae). The influence of juvenile hormone ( $\mathrm{JH})$ on the ovarian development of worker larvae of Apis mellifera was analyzed, taking into account the trophic determination of the castes. The workers control the larval feeding in order to promote caste differentiation, which is regulated by the production and availability of this hormone. The hypothesis tested was that the action of juvenile hormone is capable of protecting or preventing the degeneration of the ovaries in worker larvae. A preparation of $1 \mu 1$ of juvenile hormone dissolved in hexane at a concentration of $1 \mu \mathrm{g} / \mu \mathrm{l}$ was applied topically to 2- to 5-day-old larvae. The morphology of the ovaries was evaluated on the days following the application, until the larvae were 6 days old. The controls consisted of larvae to which $1 \mu$ of hexane was applied, and larvae that received no treatment. The effect of juvenile hormone varied according to the age of the larvae to which it was applied, and this effect was greatest in 3-day-old larvae.
\end{abstract}

KEYWORDS. Castes; ovariole number; post-embryonic development; worker.

RESUMO. Efeitos da aplicação tópica de hormônio juvenil sobre o desenvolvimento dos ovários de larvas de operárias de Apis mellifera Linnaeus (Hymenoptera, Apidae). A influência do hormônio juvenil sobre o desenvolvimento do ovário de larvas de operárias de Apis mellifera foi analisada levando em conta a determinação trófica das castas, segundo a qual a alimentação larval é controlada pelas operárias de maneira a promover uma diferenciação de castas controlada pela produção e disponibilidade desse hormônio. A hipótese testada é que a ação do hormônio juvenil seja capaz de proteger ou prevenir a degeneração nos ovários das larvas de operárias. Foi feita aplicação tópica de $1 \mu 1$ de hormônio dissolvido em hexano na concentração de $1 \mu \mathrm{g} / \mu \mathrm{l}$ do segundo até o quinto dia de vida larval, e a morfologia dos ovários avaliada nos dias subseqüentes à aplicação até ao sexto dia de vida larval. Como controles foram utilizadas larvas nas quais se aplicou $1 \mu \mathrm{l}$ de hexano e larvas que não receberam nenhum tratamento. Constatou-se que o efeito do hormônio juvenil varia conforme a idade larval em que é aplicado e que este efeito foi maior quando a aplicação foi feita no terceiro dia de vida larval.

PALAVRAS-CHAVE. Castas; desenvolvimento pós-embrionário; número de ovaríolos; operária.

Apis mellifera Linnaeus (1758) é uma abelha eussocial com marcado dimorfismo entre operárias e rainhas, sendo a diferença no desenvolvimento ovariano um clássico exemplo deste dimorfismo. Os ovários são do tipo meroísticos politróficos com células nutridoras associadas a cada ovócito. Em rainhas são bem desenvolvidos, tendo centenas de ovaríolos ativos, enquanto operárias apresentam poucos ovaríolos por ovário, geralmente inativos, (Ribbands 1953; Snodgrass 1956; Jung-Hoffmann 1966).

O período larval no qual se iniciam as diferenças no desenvolvimento dos ovários de rainhas e operárias é controverso, existindo indicações da ocorrência de diferenças morfológicas já no terceiro instar (Reginato \& Cruz Landim 2001) ou somente no quinto (Capella \& Hartfelder 2002).

No caso de A. mellifera, os nutrientes oferecidos às larvas pelas operárias são os desencadeadores do dimorfismo reprodutivo observado nessa espécie (Haydak 1970; Kucharski et al. 2008). A nutrição larval após os primeiros dois ou três dias da eclosão determina se o programa de desenvolvimento será direcionado para rainha ou operária, sendo que a diferenciação entre as duas castas está principalmente na qualidade do alimento oferecido às larvas pelas operárias nutridoras. A partir do segundo ou terceiro dia de vida larval as operárias alimentam as larvas que se desenvolverão em rainhas exclusivamente com geléia real, um produto de suas glândulas hipofaríngeas, com alguma contribuição das glândulas mandibulares (Jung-Hoffmann 1966). Segundo Beetsma (1979), o açúcar presente nesse alimento seria um fator importante que estimularia a sua ingestão pela larva e indiretamente, regularia a atividade dos corpora allata, possívelmente através de ação sobre a produção do hormônio PTTH pelas células neurosecretoras do cérebro (Simões et al. 1997) afetando, dessa forma, a produção de hormônio juvenil (HJ).

$\mathrm{O} \mathrm{HJ}$ tem sido apontado como um dos principais agentes envolvidos com o desenvolvimento de polimorfismo ou polifenismo, dado o seu papel no programa de desenvolvimento celular (Dixon \& Shuel 1963; Campos 1978, 1979; Rembold 1987; Rachinsky \& Hartfelder 1990, 1991; Hartfelder \& Rembold 1991; Hatfelder \& Emlen 2005). O alto 
título deste hormônio durante o terceiro dia de desenvolvimento larval (Rembold et al. 1992) induz a diferenciação em rainha, enquanto baixas concentrações, resultam no desenvolvimento de uma operária. Os títulos altos encontrados em larvas de rainhas protegem os ovários larvais de morte celular maciça causada por desintegração da actina do citoesqueleto dos ovaríolos (Capella \& Hartfelder 2002).

Tem se tornado mais evidente em trabalhos recentes, a noção de que o HJ é o fator endógeno decisivo na indução da diferenciação das rainhas nas abelhas. Além dos aspectos nutricionais que envolvem a dieta da rainha, doses extras do hormônio aplicadas externamente em larvas de operárias podem induzir o desenvolvimento de características associadas às rainhas (Wilde 1976; Dietz et al. 1979; Hartfelder et al. 2005; Barchuk et al. 2007). Parece, portanto, que a variação trófica na fase larval influencia a produção do HJ (Dixon \& Shuel 1963), e este modula a diferenciação das castas.

O esclarecimento de aspectos da ação do HJ é de extrema importância para o entendimento da determinação de castas nestes insetos e, portanto, a hipótese testada neste trabalho é que a aplicação tópica de $\mathrm{HJ}$ a partir do segundo dia de vida larval seja capaz de proteger ou prevenir a degeneração nos ovários das larvas de operárias, visto que trabalhos recentes mostram que a diferenciação entre os ovários de rainhas e operárias é mais precoce do que se pensava anteriormente.

\section{MATERIALE MÉTODOS}

Foram utilizadas larvas de A. mellifera, do segundo ao sexto dia de vida, após eclosão do ovo, a partir de postura controlada de uma mesma rainha em colônias mantidas no Biotério do Instituto de Biociências, UNESP, Rio Claro.

Os tratamentos foram aplicados em lotes de larvas do segundo, terceiro, quarto e quinto dias de vida larval, diretamente no favo. Para isso foi confeccionada uma armação de madeira com o mesmo tamanho do favo (aproximadamente $28 \times 21 \mathrm{~cm}$ ), na qual foram feitos quadrantes de $7 \times 7 \mathrm{~cm}$ com arames finos. Essa armação foi colocada sobre o favo, para identificar os lotes tratados e não tratados.

Para os tratamentos utilizou-se aplicação tópica no dorso da larva de $1 \mu 1$ de HJ III (SIGMA) A aplicação foi feita com micropipetador automático, volume de $2 \mu \mathrm{l}$, da marca Gilson. O hormônio foi diluído em hexano na concentração de $1 \mu \mathrm{g} / \mu \mathrm{l}$. Em cada quadrante foi aplicado HJ em 100 a 150 larvas, assim como, em outro quadrante do mesmo favo, a mesma dose de seu solvente o hexano, no mesmo número de larvas. Portanto, foram feitos dois controles para o tratamento com $\mathrm{HJ}$ : larvas tratadas com o solvente hexano e larvas sem tratamento algum. A dosagem de hormônio empregada, $1 \mu \mathrm{g} / \mu \mathrm{l}$, é a usual nesse tipo de tratamento (Farinha et al. 1988; Abdalla et al. 2001; Paes de Oliveira \& Cruz-landim 2001; Pinto et al. 2002).

Para o controle da idade as larvas foram obtidas a partir de uma rainha mantida confinada em um favo por tela excluidora, durante aproximadamente 6 horas. Depois da postura o favo foi transferido para uma colônia sem rainha para que as larvas se desenvolvessem. Para confirmação e maior confiabilidade dos dados um outro favo foi oferecido a mesma rainha em outro momento distinto e o experimento foi repetido da mesma maneira.

A primeira coleta de cada lote foi realizada um dia após aplicação do HJ e do hexano. Daí em diante as larvas foram coletadas de 24 em 24 horas após as aplicações. Foram coletadas 10 larvas de cada tipo de tratamento, por quadrante, do mesmo favo. Os controles não tratados também foram coletados, no mesmo favo, com as mesmas idades. Uma amostra de 10 larvas com as idades correspondentes às do tratamento tiveram a cápsula cefálica medida para determinação do instar em que se encontravam utilizando a regra de Dyar (1890).

Para verificar a influência dos tratamentos sobre a diferenciação dos ovários foram preparadas lâminas histológicas de larvas fixadas em mistura de Bouin aquoso, durante 2 horas. Para garantir melhor fixação o tegumento das larvas foi perfurado com estilete em várias regiões do corpo. Após a fixação, o material foi desidratado em etanol e incluído em historesina Leica seguindo as instruções do fabricante.

Com o objetivo de padronizar a posição dos cortes, todas as larvas foram incluídas na mesma posição, correspondente ao terço mediano do corpo voltado para cima na resina. Esta região é onde se encontram os ovários e, portanto, a região onde passaram os primeiros cortes, pegando os ovários sempre em cortes longitudinais e os ovaríolos em cortes transversais. Foram feitos cortes seriados com $5 \mu \mathrm{m}$ de espessura os quais foram recolhidos em lâminas histológicas. Depois de secas, as lâminas receberam coloração com hematoxilina e eosina, seguindo os procedimentos rotineiros, para verificação da morfologia e realização das medidas, as quais foram tomadas nas secções que apresentaram os ovários em posição mediana. Foi analisada a morfologia e mensurada a área dos cortes dos ovários e contado o número de ovaríolos das larvas sob efeito dos tratamentos com HJ e nos controles. Tanto a contagem do número de ovaríolos como a medida da área dos ovários foram feitas em 10 diferentes larvas. As áreas e número de ovaríolos foram obtidos com a utilização de um microscópio Axioskop, provido de sistema Axiohome. Os dados foram submetidos à análise de variância (Two Way Anova) para comparação das médias, ao nível de 5\% de significância, a um teste pos-roc de Dunnet e a uma análise de regressão para detectar possível relação entre o número de ovaríolos e a área dos ovários.

\section{RESULTADOS}

Nas condições do experimento as medidas das cápsulas cefálicas das larvas feitas na amostra por idade, tanto para as que sofreram aplicação do hormônio e hexano, quanto para as controle, o instar larval coincidiu com a idade das larvas em dias, estando, portanto a larva com dois dias de vida no segundo instar, com três dias no terceiro e assim por diante. Todas as larvas coletadas no $6^{\circ}$ dia de vida larval, tratadas e não tratadas, estavam no final do quinto instar larval, na fase de tecelagem do casulo ou de larva pré-defecante. No entanto, como não foram feitas medidas individuais para cada larva 
utilizada e sim computado o tempo de desenvolvimento em dias, todos os resultados referir-se-ão as idades, ficando a correspondência ao instar apenas como referência para as condições em que o trabalho foi realizado.

Todos os cuidados foram tomados para que pudesse ser avaliado apenas o efeito dos tratamentos sem influência dos procedimentos adotados sobre os resultados. Assim, foi previamente feito um teste piloto para averiguar se a manipulação das larvas ou seu desenvolvimento em colônia sem rainha causava alguma alteração. Verificou-se que os tratamentos não alteraram a cronologia do desenvolvimento, nem a taxa de mortalidade, a qual nunca ultrapassou $10 \%$ do total das larvas submetidas aos testes. As condições de criação das larvas e os tratamentos também não alteraram sua alimentação pelas operárias. Nenhuma realeira apareceu e todas as larvas coletadas apresentaram o tamanho e características da idade/instar.

A aplicação do HJ e hexano afetou o desenvolvimento dos ovários das larvas de operárias, seja quanto ao tamanho e o número de ovaríolos (Fig. 1), quanto a morfologia dos ovários (Fig. 2), quando analisados os resultados no sexto dia de vida larval. A natureza do efeito variou conforme a idade larval na qual foi aplicado tanto o HJ quanto o hexano. A análise estatística das áreas dos ovários de larvas ao final do desenvolvimento, no sexto dia de vida, revelou diferenças significativas entre as médias (Fig.1) em relação ao controle sem nenhum tratamento, quando a aplicação do $\mathrm{HJ}$ e hexano foram feitas no segundo $(\mathrm{F}=29,01, \mathrm{p}=0,00, \mathrm{n}=90)$ e terceiro dia de vida larval $(\mathrm{F}=19,92, \mathrm{p}=0,00, \mathrm{n}=64)$. Não ocorreram diferenças significativas quando as aplicações foram feitas no quarto ( $\mathrm{F}=1,848, \mathrm{p}=0,153, \mathrm{n}=47)$ e quinto dia de desenvolvimento larval $(\mathrm{F}=1,860, \mathrm{p}=0,186, \mathrm{n}=24)$. Quanto ao número de ovaríolos ocorreram diferenças significativas entre as médias, com relação ao controle sem nenhum tratamento, no segundo ( $\mathrm{F}=6,142, \mathrm{p}=0,00, \mathrm{n}=90)$, terceiro $(\mathrm{F}=10,03, \mathrm{p}=0,00, \mathrm{n}=64)$, quarto $(\mathrm{F}=8,29, \mathrm{p}=0,00, \mathrm{n}=47)$ e quinto $(\mathrm{F}=30,63, \mathrm{p}=0,00, \mathrm{n}=24)$ dia de aplicação de $\mathrm{HJ}$ e hexano. O teste de Dunnett apontou diferenças significativas entre as áreas dos ovários das larvas que sofreram aplicação de $\mathrm{HJ}$, com relação ao controle sem nenhum tratamento no segundo $(\mathrm{p}=0,00)$, e terceiro $(\mathrm{p}=0,00)$, porém as que sofreram aplicação de hexano apresentaram diferenças significativas somente no segundo dia $(p=0,00)$. $O$ mesmo teste apontou diferenças entre o número de ovaríolos de larvas que sofreram aplicação de $\mathrm{HJ}$ em relação ao controle sem nenhum tratamento no segundo $(\mathrm{p}=0,00)$, terceiro $(\mathrm{p}=0,00)$, quarto $(\mathrm{p}=0,002)$ e quinto $(\mathrm{p}=0,001)$ dias de vida. O número de ovaríolos das larvas que sofreram aplicação de hexano apresentou diferenças significativas no quinto dia $(\mathrm{p}=0,001)$ de vida larval. O teste de regressão linear foi significativo, sendo detectada uma correlação positiva entre o número de ovaríolos e a área dos ovários $\left(\mathrm{r}^{2}=0,268, \mathrm{~b}=0,24, \mathrm{~F}=24,92\right.$, $\mathrm{p}=0,00)$.

Quanto à morfologia, as maiores mudanças foram observadas quando a aplicação de $\mathrm{HJ}$ e hexano foi feita no quinto dia de vida larval. Os efeitos morfológicos, neste caso foram evidentes no dia seguinte à aplicação (Fig.2), embora a
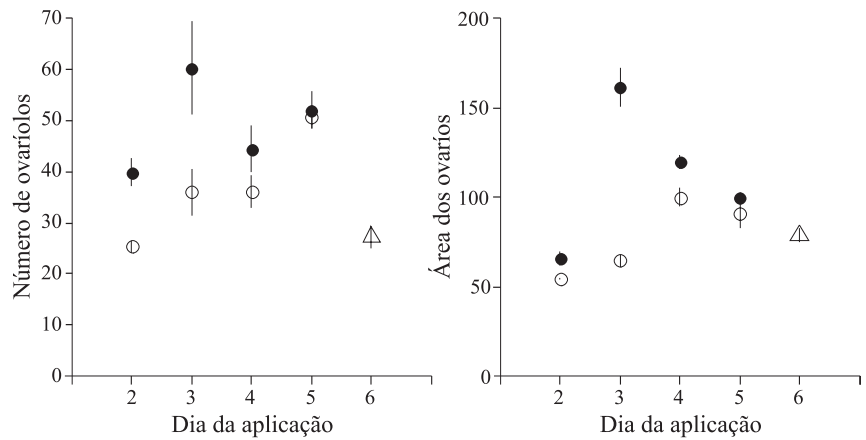

Fig. 1. Médias das áreas e desvios padrões dos números de ovaríolos e das áreas dos ovários $\left(\mathrm{u}^{2}\right)$ das larvas de sexto dia de vida de A. mellifera sob efeito da aplicação de $\mathrm{HJ}(\bullet)$, hexano $(\mathrm{O})$ e do controle $(\Delta)$ sem nenhum tratamento.

análise morfométrica não tenha apontado diferenças significativas entre as médias das áreas dos ovários.

Deve-se notar, contudo, que as larvas tratadas com $\mathrm{HJ}$ em qualquer dia de aplicação apresentaram no sexto dia a forma dos ovários mais ovalada em relação ao tratamento com hexano e ao controle sem nenhum tratamento, assim como uma cápsula externa mais delgada e tecido de preenchimento menor entre os ovaríolos (Fig. 2) o que configura efeito do hormônio na forma e estrutura do ovário.

Embora as áreas dos ovários das larvas com seis dias de idade sob efeito do HJ aplicado no segundo e terceiro dias apresentassem diferenças significativas, foi só com a aplicação no terceiro dia que as médias tanto das áreas dos ovários como do número de ovaríolos foram maiores que as médias das áreas dos ovários de larvas de mesma idade sem nenhum tratamento (Fig.1). A aplicação do hormônio no quarto e quinto dias não apresentou diferenças significativas em relação ao controle, quanto às áreas dos ovários, embora as médias do número de ovaríolos tenham sido maiores (Fig.1) e apresentado diferenças significativas. Ainda assim foram menores do que quando a aplicação foi feita no terceiro dia (Fig. 1).

Com relação ao tratamento feito com hexano, as médias das áreas dos ovários e do número de ovaríolos (Fig. 1) no sexto dia de vida larval, independente do dia de aplicação, sempre foram menores que as das larvas tratadas com HJ.

\section{DISCUSSÃO}

Nos trabalhos referentes ao efeito do $\mathrm{HJ}$ sobre a fisiologia de abelhas, não costuma ser levado em conta o efeito isolado do veículo de aplicação do hormônio (Wirtz 1973; Rembold et al. 1974; Ansencot \& Lensky 1976; Copijn et al. 1979; Dietz et al. 1979; Hartfelder \& Engels 1998), no entanto, em alguns trabalhos nos quais foi acrescentado um controle sem qualquer tratamento verificou-se que o solvente do hormônio não é inerte (Farinha et al.1988; Paes de Oliveira \& Cruz Landim 2001; Pinto et al. 2002). O solvente mais comumente usado para o HJ é acetona, mas devido à comprovação de que este tem efeito citotóxico acentuado (Farinha et al.1988; Abdalla et al. 2001; Paes de Oliveira \& Cruz-Landim 2001; Pinto et al. 


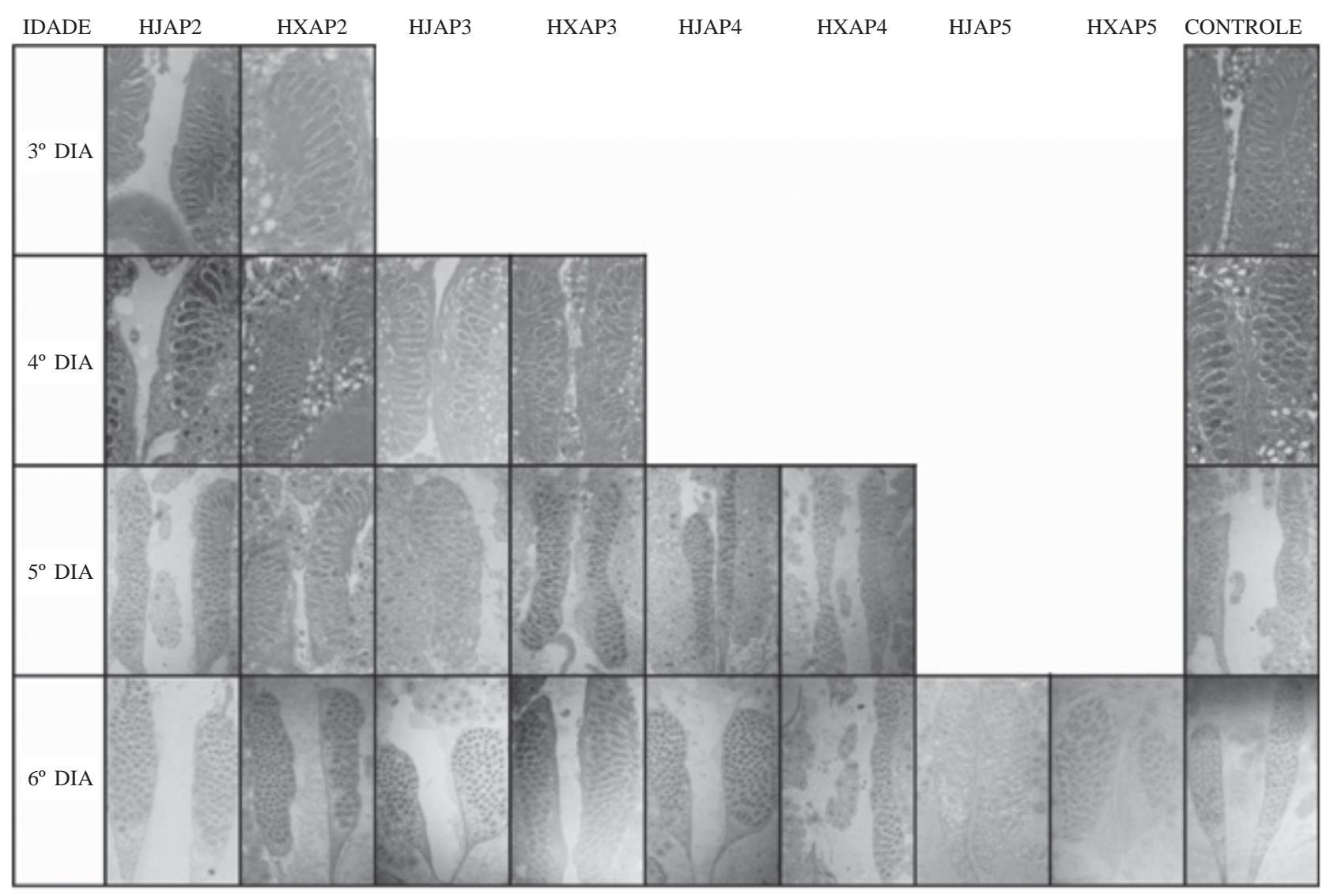

Fig. 2. Aspectos morfológicos do desenvolvimento ovariano de larvas de operárias de A. mellifera comparando diferentes dias de aplicação (1 $\mu \mathrm{g} /$ $\mu 1)$ do hormônio juvenil e hexano com o controle não tratado de mesma idade. HJAP2 $=\mathrm{HJ}$ aplicado no $2^{\circ}$ dia $\left(\right.$ aumentos $3^{\circ} \mathrm{e} 4^{\circ} \mathrm{dias}=125 \mathrm{X}, 5^{\circ} \mathrm{e}$ $6^{\circ}$ dias $\left.=100 \mathrm{X}\right) \mathrm{HXAP} 2=$ hexano aplicado no $2^{\circ}$ dia (aumentos $3^{\circ}$ e $4^{\circ}$ dias $=125 \mathrm{X}, 5^{\circ}$ e $6^{\circ}$ dias $\left.=100 \mathrm{X}\right)$, HJAP $3=\mathrm{HJ}$ aplicado no $3^{\circ}$ dia $($ aumento $4^{\circ} \mathrm{dia}=125 \mathrm{X}, 5^{\circ}$ e $6^{\circ}$ dias $=100 \mathrm{X}$ ), HXAP $3=$ hexano aplicado no $3^{\circ}$ dia (aumento $4^{\circ}$ dia $=125 \mathrm{X}, 5^{\circ}$ e $6^{\circ}$ dias $=100 \mathrm{X}$ ), HJAP4 $=\mathrm{HJ}$ aplicado no $4^{\circ}$ dia (aumento $5^{\circ}$ e $6^{\circ}$ dias=100X), HXAP4 $=$ hexano aplicado no $4^{\circ}$ dia (aumento $5^{\circ}$ e $6^{\circ}$ dias $=100 \mathrm{X}$ ), HJAP5 $=$ HJ aplicado no $5^{\circ}$ dia $($ aumento $6^{\circ} \mathrm{dia}=100 \mathrm{X}$ ), HXAP5 $=$ hexano aplicado no $5^{\circ}$ dia. (aumento $6^{\circ} \mathrm{dia}=100 \mathrm{X}$ ), Controle (aumento $3^{\circ}$ e $4^{\circ}$ dias $=125 \mathrm{X}, 5^{\circ}$ e $6^{\circ} \mathrm{dia}=100 \mathrm{X}$ ).

2002) foi feita a tentativa de se usar um veículo diferente, neste caso o hexano. Entretanto, observou-se que este também provoca alterações na fisiologia dos indivíduos tratados, as quais dificultam a análise dos resultados finais. Embora algumas variações nos resultados possam estar relacionadas à volatilidade do hexano devido à alta temperatura no momento de aplicação no favo, aumentando ou diminuindo os efeitos do mesmo, ou ainda à sensibilidade das larvas ao hexano na idade em que receberam a aplicação, os seus efeitos não revelaram toxicidade capaz de interromper o desenvolvimento ou alterar a sobrevivência das larvas tratadas.

$\mathrm{O}$ efeito dos tratamentos seja com o $\mathrm{HJ}$ ou com hexano variaram conforme a idade das larvas quando da aplicação. Isto se deve a variações da sensibilidade das larvas conforme a fase do desenvolvimento em que se encontram. No caso específico do hormônio esta sensibilidade é maior em determinadas fases da vida larval (Wirtz 1973). Assim, o fato do efeito sobre o desenvolvimento dos ovários ter sido menos evidente quando o tratamento com $\mathrm{HJ}$ é feito no segundo dia pode ser devido a não sensibilidade dos ovários ao hormônio nesta fase, em que ainda não há diferenças alimentares entre as larvas de uma e outra casta.
Durante o curso de desenvolvimento pré-imaginal em $A$. mellifera, os títulos de HJ sofrem variações, sendo relativamente elevados durante os primeiros instares larvais, decrescendo no último instar precedendo a fase pré-pupal de tecer o casulo, aumentando um pouco durante a tecelagem e a pré-pupa e novamente diminuindo durante a pupação (Rachinsky et al. 1990). Isto explicaria porque a aplicação do HJ no terceiro dia de vida larval só apresenta efeito no sexto dia, ou seja, no fim do desenvolvimento larval. A aplicação do hormônio exógeno nessa fase em que ocorre a mudança de dieta das larvas e o título do hormônio é alto, provavelmente altera pouco o título do HJ endógeno.

Este efeito observado somente no sexto dia de vida larval está de acordo com resultados de Reginato \& Cruz-Landim (2003), os quais descreveram que no desenvolvimento normal dos ovários de rainhas e operárias de A. mellifera as diferenças de tamanho só se manifestam a partir do quarto instar da vida larval, embora a diminuição do número de ovaríolos nos ovários das operárias ocorra a partir do terceiro instar larval. As diferenças entre os ovários de rainhas e operárias só se tornam completamente visíveis no final da fase larval, quando a cápsula que envolve os ovários se rompe, deixando os 
ovaríolos livres, mostrando então o número de ovaríolos muito menor (Reginato \& Cruz-Landim, 2002). Portanto, o efeito mais significativo (Antonialli-Junior \& Cruz Landim 2006) da aplicação do HJ no terceiro dia de vida larval está de acordo com o curso natural do desenvolvimento do ovário.

Da mesma forma os ovários de larvas sem nenhum tratamento apresentaram áreas maiores que os das larvas tratadas com HJ no segundo dia (Fig. 1), o que provavelmente esteja relacionado à maior quantidade do tecido de preenchimento entre os ovaríolos ou à espessura maior da cápsula externa (Reginato \& Cruz-Landim 2001) como pode ser constatado na Fig. 2. A este respeito, Reginato \& CruzLandim (2003) observaram que a diminuição do número de ovaríolos nos ovários das operárias não é correspondentemente acompanhada por diminuição de seu tamanho, o qual só se manifesta completamente no final da fase larval, quando a cápsula que envolve os ovários se rompe, deixando os ovaríolos livres. No entanto, a análise de regressão apontou uma correlação positiva entre a área dos ovários e numero de ovaríolos, o que indica, neste caso, que à medida que a área dos ovários regride o numero de ovaríolos também diminui.

Quando a aplicação do hormônio é feita em larvas de quinto dia de vida, quando os níveis de HJ estão baixos causam respostas mais imediatas, evidenciando que existem etapas durante o desenvolvimento, nas quais o inseto é mais susceptível a influência das mudanças de títulos do hormônio juvenil (Nijhout \& Wheeler 1982; Nijhout 1994).

Experimentos realizados por Wirtz (1973) com A. mellifera demonstraram conclusivamente um maior efeito do $\mathrm{HJ}$ e de seus análogos sintéticos na diferenciação de características de rainhas quando as aplicações foram feitas no último instar larval de operárias (Rembold et al. 1974; Ansencot \& Lensky 1976; Copijn et al. 1979; Dietz et al. 1979). De fato a maior degeneração ovariolar, da qual resulta a grande diferença entre os ovários das rainhas e das operárias ocorre ao fim da fase larval (Cruz-Landim 2004). É por isso que a regressão do número de ovaríolos pode ser experimentalmente inibida pela aplicação tópica de HJ no início do quinto instar em larvas de operárias (Hartfelder \& Engels 1998). Contudo, apesar do efeito da aplicação do HJ no quinto dia ser mais visível, não é durante o último estágio larval, que as diferenças de títulos deste hormônio são máximas entre larvas propensas a serem rainhas e operárias, mas no terceiro instar larval, como descrito por meticulosos estudos de Rembold et al. (1992).

Outro fato importante e descrito aqui, é que os efeitos da aplicação dos tratamentos não são pontuais, ou seja, o efeito do hormônio e do hexano em um dado momento prolonga-se ou é visível durante as idades seguintes. Segundo Reginato \& Cruz-landim (2001) nas larvas de operárias do segundo para o terceiro instar, os ovários aumentam em área $10 \%$. Do terceiro para o quarto há um aumento de cerca de $63 \%$. A partir deste momento os ovários das operárias diminuem de tamanho. Nossos resultados corroboram esses dados, pois como já foi dito a aplicação de HJ e hexano parece mostrar pouco efeito no desenvolvimento ovariano até o quarto dia (Fig. 2).
Em conclusão, pode-se dizer que mesmo com a interferência do solvente foi possível verificar pelos resultados que o tratamento com HJ afeta positivamente a preservação dos ovários das larvas das operárias. Os resultados apresentados mostram que a aplicação do HJ no terceiro dia de vida larval foi mais significativa sugerindo que o ponto crítico da diferenciação de castas em A. mellifera, no que se refere ao ovário, está em uma idade larval anterior ao que se pensava, já a partir do terceiro dia como mostrado por Reginato \& Cruz landim (2002) e Antonialli-Junior \& Cruz Landim (2006).

Agradecimentos. Agradecemos à desenhista Cristiane Márcia Mileo pelo auxílio com as figuras. Ao Prof. Dr. Yzel Rondon Soarez pelo auxílio com as análises estatísticas. Aos consultores que com sua leitura cuidadosa e criteriosos comentários contribuíram para a maior clareza do trabalho. À Janet W. Reid do Virginia Museum of Natural History pela revisão do Abstract. Ao CNPq (Processo 351016/94-5) e a FAPESP (Processo: 98/15057-6) pelo apoio financeiro.

\section{REFERÊNCIAS}

Abdalla F. C; L. F. Gracioli \& H. C. Salles. 2001. Effect of topical application of juvenile hormone $(\mathrm{JH})$ in honeybee worker larvae on the development of Dufour's and Koschewnikow's. Sociobiology 37: 185-191.

Antonialli-Junior, W. F \& C. Cruz-Landim. 2006. Effect of topical application of juvenile hormone on the occorrunce of cell death in the larvae of honeybee (Apis mellifera). Brazilian Journal of Morphological Sciences 23: 377-383.

Asencot, M. \& Y. Lensky. 1976. The effect of soluble sugars and juvenile hormone on the differentiation of the female honeybee (Apis mellifera L.) larvae to queens. Insect biochemistry 18: 693-700.

Barchuk, A. R; A. S. Cristino; R. Kucharski; L. F. Costa; Z. L. P Simões \& R. Maleszka. 2007. Molecular determinants of caste differentiation in the highly eusocial honeybee Apis mellifera. BMC Developmental Biology 7: 1-19.

Beetsma, J. 1979. The process of queen-worker differentiation in the honeybee. Bee World. 60: 24-39.

Capella, I. C. S. \& K. Hartfelder. 2002. Juvenile-hormone-dependent interaction of actin and spectrin is crucial for polymorphic differentiation of larval honey bee ovary. Cell and Tissue Research 307: 265-72.

Campos, L. A. O. 1978. Sex determination in bees. VI. Effect of a juvenile hormone analogue in males and females of Melipona quadrifasciata (Apidae). Journal of the Kansas Entomological Society 51: 228-234.

Campos, L. A. O. 1979. Determinação do sexo nas abelhas. XIV Papel do hormônio Juvenil na diferenciação das castas na subfamília Meliponinae (Hymenoptera, Apidae).Revista Brasileira de Biologia 39: 965-971.

Copijn, G. M.; J. Beetsma \& P. Wirtz. 1979. Queen differentiation and mortality after application of different juvenile hormone analogues to worker larvae of the honeybee (Apis mellifera L.). Proceedings of the Section of Sciences, Koninklijke Akademie van Wetenschappen te Amsterdam 82: 29-42.

Cruz-landim, C. 2004. Biologia do Desenvolvimento em abelhas. Depto. Biologia, Instituto de Biociências, Unesp/Rio Claro. Disponível em http://www.rc.unesp.br/ib/biologia/ Carminda.html.

Dietz, A.; H. R. Herman \& M. S. Blum. 1979. The role of exogenous JH-I, JH-II, JH-III and anti-JH (Precocene II) on the queen induction of 4.5 day-old worker honey bee. Journal of Insect Physiology 25: 503-512.

Dixon, S. E. \& R. W. Shuel. 1963. Studies in the mode of royal jelly, in honeybee development III. The effect of experimental variation 
in diet on growth and metabolism of honeybee larval. Canadian Journal of Zoology 41: 733-9.

Dyar, H. G. 1890. The number of molts of lepidopterous larvae. Psyche 5: 420-422.

Farinha, E. K.; L. M. Torneiros; R. L. M. Silva de Moraes \& C. CruzLandim. 1988. Influência hormonal sobre o conteúdo de DNA nas células da glândula salivar larval de Melípona quadrifasciata anthidioides Lep. (APIDAE, MELIPONINAE). I. Hormônio Juvenil. Naturalia 13: 75-83.

Hartfelder, K. \& H. Rembold. 1991. Caste-specific modulation of juvenile hormone III content and ecdysteroid titer in postembryonic development of the stingless bee, Scaptotrigona postica. Journal of comparative physiology. Part b: biochemical, systems, and C Environmentalphysiology 160: 607-620.

Hartfelder, K. \& W. Engels. 1998. Social insect polymorphism: Hormonal regulation of plasticity in development and reproduction in the honeybee. Current Topics in Developmental Biology 40: $45-77$.

Hartfelder, K. \& D. J. Emlen. 2005. Endocrine control of insect polyphenism. In: Gilbert, L. I; Latrou, K; Gill, S. S. (Edit), Comprehensive Insect Molecular Science. Oxford; \#: 651703.

Haydak, M. H. 1970. Honey bee nutrition. Annual Review of Entomology 15: 143-156.

Jung-Hoffmann, I. 1966. Die Determination von Konigin und Arbeiterin der Honigbiene. Zeitschrift Bienenforschung 8: 296-322.

Kucharski, R.; J. Maleszka; S. Foret \& R. Malszka. 2008. Nutricional controlo $f$ reprodutive status in honeybbes via DNA methylation. ScienceDOI: $10.1126 /$ science.1153069.

Nijhout, F. H. 1994. Insect Hormones. Pricenton, Pricenton University Press, $267 \mathrm{p}$.

Nijhout, F. H. \& D. E. Wheeler. 1982. Juvenile hormone and the physiological basis of insect polymorphisms. Quarterly Review of Biology 57: 109-133.

Paes de Oliveira, V. T. \& C. Cruz-Landim. 2001. Experimental Control of the Extra Doses of Juvenile Hormone on Bee Development: The case of the wax glands of Apis mellifera (Hymenoptera: Apidae). Sociobiology 38: 513-521.

Pinto, L. Z.; K. Hartfelder; M. M. Bitondi \& Z. L. P. Simões. 2002. Ecdysteroid titers in pupae of highly social bees relate to distinct modes of caste development. Journal of Insect Physiology 48: $783-790$

Rachinsky, A.; C. Strambi; A. Strambi \& K. Hartfelder. 1990. Caste and metamorphosis: hemolymph titers of juvenile hormone and ecdysteroids in last instar honeybee larvae. General and
Comparative Endocrinology 79: 31-8.

Rachinsky, A. \& K. Hartfelder. 1990. Corpora allata activity, a prime regulating element for caste-especific juvenile hormone titre in honey bee larvae (Apis mellifera carnica). Journal of Insect Physiology 36: 189-194.

Rachinsky, A. \& K. Hartfelder. 1991. Differential production of juvenile hormone and its desoxy precursor by corpora allata of honey bee during a critical point of caste development. Naturwissenschaften 78: $270-272$.

Reginato, R. D. \& C. Cruz-Landim. 2001. Diferentiation of the worker's ovary in Apis mellifera L. (Hymenoptera, Apidae) during life of the larvae. Invertebrate Reproduction and Development 39 : 127-134.

Reginato, R. D. \& C. Cruz-Landim. 2002. Morphological characterization of cell death during the ovary differentiation in worker honey bee. Cell Biology International 26: 243-251.

Reginato, R. D. \& C. Cruz-Landim. 2003. Ovarian growth during larval development of queen and worker of Apis mellifera (Hymenoptera: Apidae): A morphometric and histological study. Brazilian Journal of Biology 63: 121-127.

Rembold, H. 1987. Regulation of Honeybee age polyethism by juvenile hormone. Behavioral Ecology and Sociobiology 20: 329-338

Rembold, H; C. H. Czoppelt; M. Grune; B. Lacner; J. Pfeffer \& E. Woker. 1992. Juvenile hormone titers during honey been embryogenesis and metamorfhosis, p. 37-43. In: Insect Juvenile Hormone Research' (B. Mauchamp, F. Couillaud, and J. C. Baehr, eds.).

Rembold, H.; C. H. Czoppelt \& P. J. Rao. 1974. Effect of juvenile hormone tratament on caste differentiation in honeybee Apis mellifera. Journal of Insect Physiology 20: 1193-1202.

Ribbands, C. R. 1953. The Behavior and Social life of Honey bee. Bee Research Association.

Simões, Z. L. P; I. C. Bolleli \& K. Hartfelder. 1997. Occurrence of a prothoracicotropic hormone-like peptide in developing nervous systemof the honey bee (Apis mellifera). Apidologie 28: 399409.

Snodgrass, R. E. 1956. Anatomy of the Honey Bee. Ithaca, New York, Comstock Publ. Ass., 334 p.

Wilde, J. 1976. An endocrine view of metamorphosis, polymorphism and diapause in insects. American Zoologist 15: 13-27.

Wirtz, P. 1973. Differentiation in the honeybee larva. A histological, electron-microscopical and physiological study of caste induction in Apis mellifera mellifera L. mededelingen van de landbouwhogeschool te wageningen 73 : 1-155. 